\title{
Investigation of Anti-archaeal Activities of Some Commercial Essential Oils on Extremely Halophilic Archaea
}

\author{
Sadi Turgut Bilgi \\ Faculty of Health Sciences, Canakkale Onsekiz Mart University, Canakkale, Turkey, 17100. \\ E-mail: stbilgi@comu.edu.tr \\ Binnur Mericli Yapici (Corresponding author) \\ Biology of Department, Faculty of Arts and Sciences, \\ Canakkale Onsekiz Mart University, Canakkale, Turkey, 17100. \\ E-mail: byapici@comu.edu.tr
}

\begin{abstract}
In this study, the anti-archaeal activity of thyme (Thymus spp.), mint (Mentha piperita), black garlic (Allium sativum) commercial essential oils were investigated on the extremely halophilic archaea. Halococcus morrhuae strain 123, Haloarchaeon 129, Halorubrum sp. 140, Natrinema pallidum strain 153, Natrialba aegyptia strain 213, Haloterrigena thermotolerans strain 415, Halococcus thailandensis strain 514 and Halobacterium noricense strain 714 were used as extremely halophilic archaea strains. SW25 broth - agar media were used for the growth of cultures. Commercial essential oils were tested at 1/10, 1/50 and 1/100 concentrations. Agar disc diffusion method was applied for antimicrobial activity. Bacitracin (B10), Novobiocin (NV5), Penicillin G (P10), Fusidic acid (FA10) antibiotic discs and Haloferax sp. HSC4 extremely halophilic archaea type culture were used as control. Commercial thyme, mint and black garlic essential oils tested in the study were found to have anti-archeal activity against all halophilic archaeal strains, 5 strains and 3 strains, respectively. According to our results, the highest inhibition zone diameters were obtained from thyme essential oil.
\end{abstract}

Keywords: Thyme, Mint, Black Garlic, Essential Oil, Archaea

DOI: $10.7176 / \mathrm{JSTR} / 5-8-07$

\section{Bazı Ticari Uçucu Yağların Aşırı Halofilik Arkeler Üzerine Anti-arkeal Aktivitelerinin Araştırılması}

\begin{abstract}
Özet
Bu çalışmada kekik (Thymus spp.), nane (Mentha piperita), siyah sarımsak (Allium sativum) ticari uçucu yağlarının aşırı halofilik arkeler üzerine anti-arkeal aktivitesi araştırılmıştır. Aşırı halofilik arke kültürü olarak Halococcus morrhuae strain 123, Haloarchaeon 129, Halorubrum sp. 140, Natrinema pallidum strain 153, Natrialba aegyptia strain 213, Haloterrigena thermotolerans strain 415, Halococcus thailandensis strain 514, Halobacterium noricense strain 714 kullanılmıştır. Kültürlerin gelişimi için SW25 sıvı ve katı besiyerleri kullanılmıştır. Ticari uçucu yağlar $1 / 10,1 / 50$ ve $1 / 100$ konsantrasyonlarda denenmiştir. Anti-arkeal aktivite için agar disk difüzyon yöntemi uygulanmıştır. Kontrol olarak basitrasin (B10), novobiyosin (NV5), penisilin G (P10), fusidik asit (FA10) antibiyotik diskleri ve tip tür olarak Haloferax sp. HSC4 aşırı halofilik arke kültürü kullanılmıştır. Çalışmada denenen ticari kekik, nane ve siyah sarımsak uçucu yağlarının sırasıyla tüm halofilik arke strainlerine, 5 straine ve 3 straine karşı anti-arkeal aktiviteye sahip olduğu belirlenmiştir. Araştırma sonuçlarına göre en yüksek inhibisyon zon çapları kekik uçucu yağından elde edilmiştir.
\end{abstract}

Keywords: Kekik, Nane, Siyah Sarımsak, Uçucu Yağ, Arke 


\section{Giriş}

Geçmişten günümüze dek uçucu yağlar antimikrobiyal özelliklerinden dolayı ilaç olarak, gıda ve kozmetik alanında kullanıla gelmiştir. Doğada bulunan farklı bitki ailelerinin tahmini olarak 1/3'ü uçucu yağ asidi içermektedir (Önenç ve Açıkgöz, 2005). Halen bitkisel uçucu yağların antibakteriyal ve antifungal özelliklerinin belirlenmesi ile ilgili bilimsel araştırmalar yoğun bir şekilde devam etmektedir. Lamiaceae familyasına ait olan kekik anti-enflamatuar, antioksidan, antiviral ve antimikrobiyal olarak kullanılan aromatik ve tıbbi bir bitkidir (Tepe ve ark., 2004; Al-Mariri ve ark., 2013; Nikolić ve ark., 2014). Günümüze kadar Avrupa, Kuzey Afrika, Asya, Güney Amerika ve Avustralya'da 928 Thymus cinsi tanımlanmıştır (Nabavi et al., 2015; Badi et al., 2004; Morales, 2002). Kendine has bir kokusu olan kekiğin yapısında bulunan özellikle timol ve carvacrol adlı aktif maddelerin antimikrobiyal etkilerinin bulunduğu bilinmektedir (Alma ve ark., 2003). Yayınlanan birçok araştırmada Thymus vulgaris ekstraklarının bakteri ve funguslar üzerine yüksek oranda antimikrobiyal aktiviteye sahip olduğu belirlenmiş̧tir (Karagöz, 2007; Yorgancıoğlu, 2012; Çolak ve Yapıcı, 2018). Farklı araştırmacılar tarafından kekik yağında bulunan fenolik bileşiklerin mikroorganizmaların hücre zarında bulunan fosfolipit tabakasını uyararak, hücre içi yaşamsal yapıların geçirgenliğini ya da mikroorganizmaların enzim sistemlerini bozduğu bildirilmiştir (Helander ve ark., 1998; Lambert ve ark., 2001).

Lamiaceae familyasına ait bir diğer önemli bitki Nane (Mentha spp.) olup uçucu yağının antimikrobiyal aktivitesinin incelendiği birçok çalışmada Gram pozitif ve Gram negatif bakterilere karşı orta derecede antimikrobiyal etkiye sahip olduğu tespit edilmiştir (Diaz ve ark., 1988; Bupesh ve ark., 2007; Jirovetz ve ark., 2018). Kekik ve nane ticari uçucu yağlarının antibakteriyel aktivitesinin araştırıldığı bir çalışmada birçok antibiyotiğe dirençli klinik izolatlara karşı uçucu yağların önemli derecede antibakteriyal aktiviteye sahip olduğu ortaya konulmuştur (Çolak ve Yapıcı, 2018). Gıda ve sağlık alanında önem taşıyan ve diğerlerinden farklı olarak Amaryllidaceae familyasında yer alan sarımsağın (Allium sativum) antibakteriyel ajan olarak Helicobacter pylori, E.coli, Lactobacillus casei gibi daha bir çok Gram negatif ve Gram pozitif bakterilere karşı etkili olduğu bilinmektedir (Cellini ve ark., 1996; Lemar ve ark., 2005). Sarımsak, ilaç ve gıda amaçlı kullanılmak üzere uzun bir geçmişi vardır (Li ve ark., 2017). Günümüzde sarımsak çoğu kültürde lezzet verici bir madde olarak da kullanılmakta ve bol miktarlarda tüketilmektedir (Bullock ve Manias, 2013). Ancak taze sarımsağın koku, tat ve gastrointestinal rahatsizlıklar gibi olumsuzluklarından dolayı son yıllarda siyah sarımsağa olan yönelim artmıştır (Ryu ve Kang, 2017). Taze sarımsağın (Allium sativum L.) kontrollü yüksek sıcaklıkta $\left(60-90^{\circ} \mathrm{C}\right)$ ve yüksek nemde $(\% 80-90)$ bir süre boyunca fermente edimesi ile elde edilen siyah sarımsağın antioksidan aktivite gibi daha iyi biyolojik faaliyetleri üzerinde durulmakta ve giderek popülerleşen fonksiyonel bir gıda olarak geliştirilmektedir (Kim ve ark., 2012; Li ve ark., 2017). Bununla birlikte siyah sarımsak ekstrelerinin bazı patojen bakteri ve maya türleri üzerine antimikrobiyal özellik gösterdiği farklı çalışmalarda gösterilmiştir (Sasaki ve ark., 2007; Jung ve Sohn, 2014; Ngan ve Giang, 2017).

Tuz birçok endüstriyel üründe mikroorganizmalara karşı koruyucu olarak kullanılmaktadır. Bazı endüstriyel ürünlerde yüksek oranda kullanılan tuz bakteriyel gelişimi önlemekte ancak aşırı halofilik arkelerin üremesini teşvik etmektedir. Aşırı halofilik arkeler organik maddeler üzerinde gelişerek pembe-kırmızı pigmenler oluşturmakta ve sahip oldukları proteolitik ve lipolitik gibi hidrolitik enzimler ile endüstriyel üründe kalite ve ekonomik kayıplara neden olmaktadır. Endüstiyel alanda koruyucu olarak kullanılacak tuza hem bakterilerin hem de arkelerin gelişimini önleyici bazı bitkisel ekstraktların ilave edilmesi bu problemin bertaraf edilmesine yardımcı olabilir. Günümüzde uçucu yağların bakteri ve funguslara karşı antimikrobiyal aktivitesi ile ilgili oldukça fazla sayıda araştırma yapılmakta ancak aşırı halofilik arkeler üzerine daha az sayıda çalışma bulunmaktadır. Bu nedenle araştırmamızda kekik, nane, siyah sarımsak ticari uçucu yağlarının aşırı halofilik arkeler üzerine anti-arkeal aktivitesi araştırılmış olup araştırma sonuçlarının literatüre ve bundan sonra yapılacak çalışmalara katkı sağlayacağı düşünülmektedir.

\section{Materyal ve Yöntem \\ 2.1.Materyal}

Çalışmada aşırı halofilik arkelere karşı anti-arkeal aktivitesi araştırılan ticari uçucu yağlar, Thymus spp. türlerinden elde edilen kekik uçucu yağı (KUY), Mentha piperita türünden elde edilen nane uçucu yağ (NUY) ve fermente edilmiş Allium sativum türünden elde edilen siyah sarımsak uçucu yağı (SUY) aktarlardan temin edilmiştir. Uçucu yağların $1: 10,1: 50$ ve $1: 100(\mathrm{v} / \mathrm{v})$ olmak üzere üç farklı konsantrasyonda anti-arkeal aktivitesi araştırılmıştır. Çalışmada 8 farklı aşırı halofilik arke kültürü kullanılmıştır. Kullanılan kültürler Bilgi ve ark. (2015) tarafından 16S rRNA dizileme yöntemiyle daha önceden tuzlanmış ham derilerden izole edilip tanımlanmış kültürler olup NCBI (The National Center for Biotechnology Information) erişim numaraları ile birlikte belirtilmiştir. Araştırmada Halococcus morrhuae strain 123 (JX481744), Haloarchaeon 129 (JX481746), Halorubrum sp. CH3 strain 140 (JX481747), Natrinema pallidum strain 153 (JX481753), Natrialba aegyptia strain 213 (JX481754), Haloterrigena

67 | $P$ a g e 
thermotolerans strain 415 (JX481761) Halococcus thailandensis strain 514 (JX481764), Halobacterium noricense strain 714 (JX481771) aşırı halofilik arke kültürleri kullanılmıştır. Kültürlerin geliştirilmesinde SW25 sıv1 ve katı besiyerleri kullanılmıştır. SW25 besiyeri 833.4 ml/1 SW 30 çözeltisi, 5 g/l maya özütü ve $20 \mathrm{~g} / 1$ agar içermiştir. SW 30 çözeltisi ise $234 \mathrm{~g} / 1 \mathrm{NaCl}, 39 \mathrm{~g} / 1 \mathrm{MgCl} 2,61 \mathrm{~g} / 1 \mathrm{MgSO} 4,1 \mathrm{~g} / 1 \mathrm{CaCl}$, $6 \mathrm{~g} / 1$ $\mathrm{KC} 1,0.25 \mathrm{~g} / 1 \mathrm{NaHCO} 3,0.7 \mathrm{~g} / 1 \mathrm{NaBr}$ ' dan oluşmuştur. Besi yerlerinin $\mathrm{pH}$ 's $1 \mathrm{~N}$ NaOH ile $\mathrm{pH} 7.5$ 'a ayarlanmıştır (Afendra et al., 2004).

\subsection{Yöntem}

Aşırı halofilik arke kültürleri SW 25 sıvı besiyerinde $37^{\circ} \mathrm{C}$ 'de 14 günde geliştirilmiştir. Anti-arkeal aktivitenin belirlenmesinde agar disk difüzyon yöntemi kullanılmıştır. Ticari uçucu yağların 1:10, 1:50 ve 1:100 (v/v) konsantrasyonları Tween 80 ile hazırlanmış (Benavides ve ark., 2012) ve 6 mm çaplı steril boş disklere $15 \mu \mathrm{l}$ emdirilmiştir. Farklı konsantrasyonda ticari uçucu yağ içeren diskler hedef mikroorganizmaların bulunduğu SW25 agar üzerine yerleştirilmiştir. $37^{0} \mathrm{C}$ 'de 14 gün inkübasyon sonunda disklerin etrafinda oluşan inhibisyon zon çapları ölçülmüştür. Tüm çalışmalar aseptik koşullarda ve dubletli olarak yürütülmüştür. Uçucu yağların pozitif kontrolü olarak Novobiosin $5 \mu \mathrm{g}$ (NV5), Penisilin G 10U (P10), Fusidik asit $10 \mu \mathrm{g}(\mathrm{FA10})$ antibiyotik diskleri negatif kontrol olarak $6 \mathrm{~mm}$ çaplı steril boş diskler kullanılmıştır. Arke kültürlerinin kontrolü olarak Yaşa ve ark. (2008) tarafindan İzmir Çamaltı tuzlasından izole edilerek tanımlanmış Haloferax sp. HSC4 aşırı halofilik arke kültürü kullanılmıştır (Montalvo Rodriguez ve ark., 1998; Yasa ve ark., 2008; Khelaifia ve Drancourt, 2012).

\section{Bulgular ve Tartışma}

Bu çalışmada anti-arkeal aktivitesi araştırılan KUY, NUY ve SUY ticari uçucu yağlarının 1:10, 1:50 ve 1:100 (v/v) konsantrasyonlarında belirlenen disk difüzyon bulguları Çizelge 1'de verilmiştir. Araştırma bulguları genel olarak değerlendirildiğinde uçucu yağların kullanım konsantrasyonu arttıkça inhibisyon zon çaplarının da arttığ 1 tespit edilmiştir.

Çizelge 1. Ticari uçucu yağların inhibisyon zon çapları

\begin{tabular}{|c|c|c|c|c|c|c|c|c|c|c|c|c|c|}
\hline \multirow{3}{*}{$\begin{array}{l}\text { Ticari Uçucu Yağlar } \\
\text { Konsantrasyon }\end{array}$} & \multicolumn{13}{|c|}{ İnhibisyon Zon Çapları (mm) } \\
\hline & \multicolumn{3}{|c|}{ KUY } & \multicolumn{3}{|c|}{ NUY } & \multicolumn{3}{|c|}{ SUY } & \multicolumn{4}{|c|}{ Kontrol } \\
\hline & $1 / 10$ & $1 / 50$ & $1 / 100$ & $1 / 10$ & $1 / 50$ & $1 / 100$ & $1 / 10$ & $1 / 50$ & $1 / 100$ & FA10 & B10 & NV5 & P10 \\
\hline H.morrhuae strain 123 & 16.75 & 12.75 & 6.00 & 6.00 & 6.00 & 6.00 & 6.00 & 6.00 & 6.00 & 22.25 & 25.25 & 15.75 & 6.00 \\
\hline N.pallidum strain 153 & 27.75 & 16.75 & 6.00 & 6.00 & 6.00 & 6.00 & 6.00 & 6.00 & 6.00 & 18.25 & 39.25 & 29.75 & 6.00 \\
\hline H.thermotolerans strain 415 & 24.00 & 13.00 & 16.50 & 6.00 & 6.00 & 6.00 & 6.00 & 6.00 & 6.00 & 22.75 & 50.25 & 49.75 & 6.00 \\
\hline H.thailandensis strain 514 & 17.00 & 12.50 & 10.25 & 10.25 & 10.25 & 6.00 & 6.00 & 6.00 & 6.00 & 24.25 & 49.25 & 29.75 & 6.00 \\
\hline Haloarchaeon 129 & $>90.00$ & $>90.00$ & $>90.00$ & 12.25 & 12.25 & 11.75 & 10.25 & 6.00 & 6.00 & 21.25 & 18.25 & 16.25 & 6.00 \\
\hline Halorubrum sp. CH3 140 & $>90.00$ & $>90.00$ & $>90.00$ & $>90.00$ & $>90.00$ & $>90.00$ & 15.75 & 14.25 & 6.00 & 19.25 & 20.25 & 16.75 & 6.00 \\
\hline N.aegyptia strain 213 & $>90.00$ & $>90.00$ & $>90.00$ & 10.25 & 6.00 & 6.00 & 6.00 & 6.00 & 6.00 & 22.25 & 33.75 & 42.75 & 6.00 \\
\hline H.noricense strain 714 & $>90.00$ & $>90.00$ & $>90.00$ & 13.75 & 10.25 & 10.25 & 15.75 & 10.25 & 10.25 & 24.75 & 49.75 & 44.75 & 6.00 \\
\hline Haloferax sp. HSC4 & $>90.00$ & $>90.00$ & $>90.00$ & 10.25 & 6.00 & 6.00 & 6.00 & 6.00 & 6.00 & 10.75 & 23.75 & 28.25 & 6.00 \\
\hline
\end{tabular}

KUY'nın 1:10 ve 1:50 konsantrasyonlarında araştırmada kullanılan arkelerin tamamına etkili olduğu tespit edilmiştir. H. morrhuae strain 123, N. pallidum strain 153, H. thermotolerans strain 415 ve H. thailandensis strain 514 kültürleri için KUY'un 1:10 kullanım konsantrasyonundan elde edilen inhibisyon zon çapları sirasiyla $16.75 \mathrm{~mm}, 27.75 \mathrm{~mm}, 24.00 \mathrm{~mm}$ ve $17.00 \mathrm{~mm}$ olarak belirlenmiştir. Haloarchaeon 129, Halorubrum sp. CH3 140, N. aegyptia strain 213, H. noricense strain 714 kültürlerinin ve kontrol olarak kullanılan Haloferax sp. HSC4 aşırı halofilik arkenin bu konsantrasyonda gelişimlerinin tamamen kontrol altına alındığ 1 tespit edilmiştir. Çalışmada kullanılan kontrol antibiyotiklerinden 8 farklı arke kültürüne karşı $06.00 \mathrm{~mm}$ ile $50.25 \mathrm{~mm}$ arasında, KUY'dan ise $06.00 \mathrm{~mm}$ ile $>90.00 \mathrm{~mm}$ arasında inhibisyon zon çap1 değerleri elde edilmiştir.

Ticari uçucu yağların inhibisyon zon çapları kontrol antibiyotikleri ile karşılaştırıldığında basitrasin ve novobiyosin antibiyotiklerine ait inhibisyon zon çaplarının denemelerde test edilen uçucu yağların tamamından yüksek olduğu tespit edilmiştir. Çalışmada 1/10 konsantrasyonunda kullanılan KUY'nın sadece $N$. pallidum strain 153 ve $H$. thermotolerans strain 415 kültürlerine karşı elde edilen inhibisyon zon çapları fusidik asit inhibisyon zon çaplarına göre daha yüksek bulunmuştur. Kontrol antibiyotiklerinden olan penisiline ait inhibisyon zon çapları ise tüm kültürler için $6.00 \mathrm{~mm}$ olarak ölçülmüştür. Halofilik arkeler peptidoglikan yapıda hücre duvarına sahip olmadığından penisilin, ampisilin ve streptomisin gibi bakterileri

68 | P a g e

www.iiste.org 
kontrol eden antibiyotiklere karşı direnç gösterirken novobiyosin, basitrasin, rifampisin ile ökaryotlarda protein sentezi inhibitörü olan anizomisin ve quinolon türevlerine karşı duyarlılık göstermektedirler (Pecher ve Böck, 1981; Bonelo ve ark., 1984). Bununla birlikte Holmes ve Dyall-Smith (1991) tarafindan novobiyosin antibiyotiğinin genel olarak öbakteriyal DNA giraz inhibitörü olduğu ve halobacteria türlerini kapsayan arkelerde de güçlü bir inhibitor olduğu ifade edilmektedir. Ayrıca protein sentez inhibitörü olan fusidik asitin de anti-archaeal bileşiklerde kullanıldığı araştırıcılar tarafından bildirilmektedir (Khelaifia ve Drancourt, 2012). Bu nedenle araştırmalarda arke ve bakteri ayırımında arkelerin penisilin, ampisilin ve streptomisin gibi antibiyotiklere karşı dirençli bakterilerin ise duyarlı olması beklenmektedir. Çalışmamızda elde edilen sonuçlar bu doğrultuda olmuş ve araştırmada denenen arkelerin tamamı fusidik asit, novibiyosin ve basitracin antibiyotiklerine karşı duyarlı bulunurken, penisilin antibiyotiğine karşı dirençli oldukları belirlenmiştir.

Çalışmada anti-arkeal aktivitesi araştırılan NUY'nın 1:10 konsantrasyonunun 8 aşırı halofilik arkeden sadece 5 tanesi üzerine anti-arkeal aktivite gösterdiği belirlenmiştir. NUY'nın 1:10 konsantrasyonu için elde edilen inhibisyon zon çapı değerleri H. thailandensis strain 514, Haloarchaeon 129, N. aegyptia strain 213, H. noricense strain 714 ve Halorubrum sp. CH3 140 için sirasıyla $10.25 \mathrm{~mm}, 12.25 \mathrm{~mm}, 10.25 \mathrm{~mm}, 13.75$ $\mathrm{mm}$ ve $10.25 \mathrm{~mm}$ ve $>90.00 \mathrm{~mm}$ olarak tespit edilmiştir. Halorubrum sp. CH3 140 kültürünün gelişiminin ise bu konsantrasyonda tamamen kontrol altına alınmış ve Halorubrum sp. CH3 140 arke kültürü dışında diğer arkelere karşı NUY'dan elde edilen inhibisyon zon çapı değerlerinin kontrol antibiyotiklerine göre daha düşük olduğu belirlenmiştir.

Diğer yandan araştırmada denenen SUY'nın 8 aşırı halofilik arke türünden sadece 3'ü üzerinde etkili olduğu belirlenmiş ve 1:10 konsantrasyondaki inhibisyon zon çapı değerleri Haloarchaeon 129, Halorubrum sp. CH3 140, H. noricense strain 714 aşırı halofilik arke kültürleri için sırasıyla $10.25 \mathrm{~mm}, 15.75 \mathrm{~mm}$ ve 15.75 mm olarak elde edilmiştir. Kontrol antibiyotiklerinden elde edilen inhibisyon zon çapı değerlerinin ise SUY'ndan elde edilen değerlerden daha yüksek olduğu tespit edilmiştir.

Ticari kekik uçucu yağının Bacillus cereus, Escherichia spp., Pseudomonas spp., Proteus mirabilis, Serratia marcescens, Shigella spp., Staphylococcus spp. hastane patojenleri üzerine antimikrobiyal aktivitesinin incelendiği bir araştırmada; ticari kekik yağının pozitif kontrol olarak kullanılan antibiyotiklerden daha yüksek inhibisyon zon çapı verdiği belirlenmiştir (Çolak ve Yapıcı, 2018). 22 Farklı klinik izolata karşı kekik yağının antibakteriyal aktivitesinin araştırıldığı farklı bir çalışmada Thymus spp. ticari uçucu yağının diğer ticari yağlara göre önemli derecede antimikrobiyal aktiviteye sahip olduğu tespit edilmiştir (Güreli ve Meriçli Yapıc1, 2018). Origanum heracleoticum L. ve Thymus vulgaris L. kullanılarak hazırlanan çözeltilerin farklı konsantrasyonlarının E. coli Tip 1, E. coli O157:H7, S. aureus, P. aeruginosa ve L. plantarum türlerine karşı antimikrobiyal aktivitesinin incelendiği bir araştırmada Thymus vulgaris içeren çözeltilerin yüksek oranda antibakteriyal aktivite sergilediği belirlenmiştir (Karagöz, 2007). Kollajen içerikli antimikrobiyal madde ilaveli krem üretimi üzerine yapılan bir araştırmada ise; en yüksek antimikrobiyal aktivitenin Origanum onites ve Thymus vulgaris içerikli formülasyonlarla elde edildiği bildirilmiştir (Yorgancığlu, 2012).

Sivropoulou ve ark. (1995) Mentha pulegium ve Mentha spicata nane türlerinden elde edilen uçucu yağların sekiz farklı Gram-pozitif ve Gram-negatif bakteriye karşı önemli antimikrobiyal aktivite sergilediğini tespit etmişlerdir. Aynı araştırmada nane esansiyel yağlarının yüksek konsantrasyonda (1/100 seyreltme) bakterisidal düşük konsantrasyonlarda (1/1000) ise bakteriostatik etki göstererek bakteri büyümesinde doza bağlı olarak bir azalma meydana geldiğini göstermişlerdir. Çalışmada test edilen esansiyel yağların ana pmentan bileşenlerinin, sadece farklı bakteriyel suşlar arasında değil, aynı bakterinin farklı suşları arasında da değişken bir antimikrobiyal aktivite sergilediğini ortaya koymuşlardır (Sivropoulou ve ark., 1995). Nane esansiyel yağının inhibisyon özellikleri üzerine yapılan diğer bir araştırmada; esansiyel yağın Staphylococcus aureus ve Salmonella enteritidis türlerinin toplam canlı sayısında önemli bir azalmaya neden olduğu bildirilmiştir (Tassou ve ark., 2000). Jirovetz ve ark. (2018) nane yağının Gram pozitif ve Gram negatif bakteriler ile Candida albicans maya türüne karşı orta-yüksek antimikrobiyal aktivite gösterdiğini belirtmişlerdir. Mentha piperita türüne ait ticari uçucu yağın onbeş farklı klinik izolata karşı antimikrobiyal aktivitesinin incelendiği bir çalışmada ise ticari nane yağı-2'nin Bacillus cereus, Staphylococcus epidermidis, Escherichia coli ve Staphylococcus lugdunensis klinik izolatlarına karşı oluşturduğu inhibisyon zon çapları sırasıyla $58.57 \mathrm{~mm}, 52.00 \mathrm{~mm}, 45.00 \mathrm{~mm}$ ve $44.25 \mathrm{~mm}$ olarak tespit edilmiştir (İdeci, 2018).

Diğer yandan taze sarımsak ve siyah sarımsağın farklı çözücülerden elde edilen ekstraktlarının antimikrobiyal aktivitelerinin incelendiği bir çalışmada tüm örneklerin Gram-negatif Salmonella ve Gampozitif Listeria monocytogenes türlerine karşı etkili olduğu tespit edilmiştir (Ngan ve Giang, 2017). Farklı bir çalışmada siyah sarımsak ekstrelerinin medikal öneme sahip metisiline dirençli Staphylococcus

69 | P a g e

www.iiste.org 
aureus, enterohemorajik Escherichia coli O157:H7, Pseudomonas aeruginosa ve Candida albicans gibi mikroorganizmalara karşı antimikrobiyal aktivite gösterdiği bildirilmiştir (Sasaki ve ark., 2007). Ancak aynı çalışmada araştırmacı önceki verilere dayanarak siyah sarımsak ekstrelerinin antimikrobiyal aktivitesinin taze sarımsak ektrelerine göre daha düşük olduğunu ifade etmiştir (Sasaki ve ark., 1999). Taze sarımsaktaki önemli etken maddelerden biri olan allisinin (Cellini ve ark., 1996; Lemar ve ark., 2005) siyah sarımsak üretim sürecinde kaybolduğu; bu nedenle siyah sarımsağın antimikrobiyal aktivitesinin önemli ölçüde azaldığı araştırıcılar tarafından belirtilmektedir (Park, 2018). Araştırmamızda siyah sarımsak uçucu yağının ve nane uçucu yağının kekik uçucu yağına göre anti-arkeal aktivitesinin daha düşük olduğu bulunmuştur. Önceki çalışmalarda siyah sarımsak özütünün ve nane uçucu yağlarının anti-arkeal aktivitesi ile ilgili bir araştırma bulunmadığından araştırma sonuçlarımız bu veriler bakımından da literatüre katkı sağlamıştır.

\section{Sonuçlar}

Çalışmamızda kullandığımız kekik, nane ve siyah sarımsak ticari uçucu yağlarının moleküler yöntemlerle tanımlanmış 8 aşırı halofilik arke üzerine anti-arkeal aktivitesi incelenmiştir. Araştırma bulgularına göre KUY; tüm arke kültürlerine, NUY; 5 Arke kültürüne ve SUY; 3 Arke kültürüne karşı anti-arkeal aktivite sergilemiştir. Önceki çalışmalarda kekik, nane ve siyah sarımsak ektraktlarının bakteri, maya, küf ve hatta virüslere karşı antimikrobiyal aktivitesi üzerine araştırmalar mevcut iken anti-arkeal aktivite ile ilgili herhangi bir literatüre rastlanmamıştır. Araştırmamızda özellikle kekik uçucu yağı diğer ticari uçucu yağlara göre arkelere karşı daha etkili bulunmuştur. Sonuç olarak bu çalışma ile bazı endüstriyel ürünlerin konservasyonunda kullanılan tuza ilave olarak kekik uçucu yağının aşırı halofilik arkelerin gelişimini kontrol etmede geniş spektrumlu doğal bir koruyucu olarak kullanılabileceği kanısına varılmıştır.

\section{Kaynaklar}

Afendra, A.S., Vargas, C., Nieto, J.J. \& Drainas, C. (2004). Gene Transfer and Expression of Recombinant Proteins in Moderately Halophilic Bacteria. Methods in Molecular Biology. 267. 209223.

Alma, M.H., Mavi, A., Yildirim, A., Digrak, M. \& Hirata, T. (2003). Screening Chemical Composition and In vitro Antioxidant and Antimicrobial Activities of the Essential Oils From Origanum syriacum L. growing in Turkey. Biological and Pharmaceutical Bulletin. 26(12). 1725-1729.

Al-Mariri, A., Swied, G., Oda, A., Hallab, L.A. (2013). Antibacterial Activity of Thymus syriacus Boiss Essential Oil and its Components against Some Syrian Gram-Negative Bacteria Isolates. Iran J Med Sci. 38(2): 180-186

Badi, H.N. Yazdani, D. Ali, S.M., Nazari, F. (2004). Effects of Spacing And Harvesting Time on Herbage Yield And Quality/Quantity of Oil in Thyme. Thymus vulgaris L. Ind. Crop. Prod.19:231236.

Benavides, S., Villalobos-Carvajal, R. \& Reyes, J. E. (2012). Physical. Mechanical and Antibacterial Properties of Alginate Film: Effect of the Crosslinking Degree and Oregano Essential Oil Concentration. Journal of Food Engineering. 110(2). 232-239.

Bilgi, S. T., Yapici, B. M. \& Karaboz, I. (2015). Determination of Hydrolytic Enzyme Capabilities of Halophilic Archaea Isolated from Hides and Skins and Their Phenotypic and Phylogenetic Identification. Journal Of The American Leather Chemists Association. 110(2). 33-42.

Bonelo, G., Ventosa, A., Megias, M. \& Ruiz-Berraquero, F. (1984). The Sensitivity of Halobacteria to Antibiotics. FEMS Microbiol. Letters. 21:341-345.

Bullock, S., \& Manias, E. (2013). Fundamentals of pharmacology. Pearson Higher Education AU.

Bupesh, G., Amutha, C., Nandagopal, S., Ganeshkumar, A., Sureshkumar, P., \& Murali, K. (2007). Antibacterial Activity of Mentha piperita L.(peppermint) From Leaf Extracts-a Medicinal Plant. Acta Agriculturae Slovenica, 89(1), 73. 
Cellini, L., Di Campli, E., Masulli, M., Di Bartolomeo, S., \& Allocati, N. (1996). Inhibition of Helicobacter pylori by Garlic Extract (Allium sativum). FEMS Immunol Med Microbiol. 13: 273277.

Çolak, A. \& Meriçli Yapıcı, B. (2018). Investigation of Antibacterial Activity of Various Essential Oils Against Seven Different Clinical Isolates. International Journal of Scientific and Technological Research. 4(3): 46-53.

Diaz, R., Quevedo-Sarmiento, J., Ramos-Cormenzana, A., Cabo, P., \& Cabo, J. (1988). Phytochemical and Antibacterial Screening of Some Species of Spanish Lamiaceae. Fitoterapia. 59: 330-333.

Güreli, Ö.S. \& Meriçli Yapici B. 2018. Determination of Antimicrobial Activity of Thyme and Black Cumin Seed Essential Oils Against Some Clinical Isolates. International Journal of Scientific and Technological Research. 4(10):84-95.

Helander, I. M., Alakomi, H. L., Latva-Kala, K., Mattila-Sandholm, T., Pol, I., Smid, E. J., ... \& von Wright, A. (1998). Characterization of the Action of Selected Essential Oil Components on Gramnegative Bacteria. Journal of agricultural and food chemistry, 46(9), 3590-3595.

Holmes, M. L., \& Dyall-Smith, M. L. (1991). Mutations in DNA Gyrase Result in Novobiocin Resistance in Halophilic Archaebacteria. Journal of bacteriology, 173(2), 642-648.

İdeci, C. (2018). Nane Esansiyel Yağlarinin Bazi Patojen Bakteriler Üzerine Antimikrobiyal Aktivitesi. Yüksek Lisans Tezi. Çanakkale Onsekiz Mart Üniversitesi Fen Bilimleri Enstitüsü.

Jirovetz, L., Buchbauer, G., Bail, S., Denkova, Z., Slavchev, A., Stoyanova, A., Schmidt, E. \& Geissler, M. (2009). Antimicrobial Activities of Essential Oils of Mint and Peppermint as Well as Some of Their Main Compounds. Journal of Essential oil research, 21(4), 363-366.

Jung, I. C., \& Sohn, H. Y. (2014). Antioxidation, Antimicrobial and Antithrombosis Activities of Aged Black Garlic (Allium sativum L.). Microbiology and Biotechnology Letters, 42(3), 285-292.

Karagöz, Z. (2007). Antimikrobiyal Özellikteki Yenilebilir Filmlerin Taze Sığır Etinin Mikrobiyolojik Ve Renk Stabilitesine Etkileri. Yüksek Lisans Tezi. Ankara Üniversitesi Fen Bilimleri Enstitüsü Gıda Mühendisliği Anabilim Dalı. Ankara. 86 s.

Khelaifia, S. \& Drancourt, M. (2012). Susceptibility of Archaea to Antimicrobial Agents: applications to clinical microbiology. Clinical Microbiology and Infection. 18(9). 841-848.

Kim, J. H., Nam, S. H., Rico, C. W., \& Kang, M. Y. (2012). A Comparative Study on the Antioxidative and Anti-Allergic Activities of Fresh and Aged Black Garlic Extracts. International journal of food science \& technology, 47(6), 1176-1182.

Lambert, R. J. W., Skandamis, P. N., Coote, P. J., \& Nychas, G. J. (2001). A Study of the Minimum Inhibitory Concentration and Mode of Action of Oregano Essential Oil, Thymol and Carvacrol. Journal of applied microbiology, 91(3), 453-462.

Lemar, K. M., Passa, O., Aon, M. A., Cortassa, S., Müller, C. T., Plummer, S., O'Rourke, B. \& Lloyd, D. (2005). Allyl Alcohol and Garlic (Allium sativum) Extract Produce Oxidative Stress in Candida albicans. Microbiology (Reading, England), 151: 3257-3265.

Li, M., Yan, Y. X., Yu, Q. T., Deng, Y., Wu, D. T., Wang, Y., Ge, Y., Li, S. \& Zhao, J. (2017). Comparison of Immunomodulatory Effects of Fresh Garlic and Black Garlic Polysaccharides on RAW 264.7 Macrophages. Journal of food science, 82(3), 765-771. doi:10.1111/1750-3841.13589.

Montalvo-Rodriguez, R., Vreeland, R. H., Oren, A., Kessel, M., Betancourt, C., \& López-Garriga, J. (1998). Halogeometricum borinquense gen. nov., sp. nov., a Novel Halophilic Archaeon from Puerto Rico. International Journal of Systematic and Evolutionary Microbiology, 48(4), 1305-1312.

71 I P a g e www.iiste.org 
Morales, R. (2002). The History, Botany and Taxonomy of the Genus Thymus. In Thyme: The Genus Thymus (pp. 1-43). Taylor \& Francis London.

Nabavi, S. M., Marchese, A., Izadi, M., Curti, V., Daglia, M., \& Nabavi, S. F. (2015). Plants Belonging to the Genus Thymus as Antibacterial Agents: From Farm to Pharmacy. Food chemistry, 173, 339347.

Ngan, N., Giang, M., \& Tu, N. (2017). Biological Activities of Black Garlic Fermented with Lactobacillus plantarum PN05 and Some Kinds of Black Garlic Presenting Inside Vietnam. Indian J Pharm Edu Res, 51(4), 672-678.

Nikolić, M., Glamočlija, J., Ferreira, I. C., Calhelha, R. C., Fernandes, Â., Marković, T., Marković, D., Giweli, A. \& Soković, M. (2014). Chemical Composition, Antimicrobial, Antioxidant and Antitumor Activity of Thymus serpyllum L., Thymus algeriensis Boiss. and Reut and Thymus vulgaris L. Essential Oils. Industrial Crops and Products, 52, 183-190.

Önenç, S. S. \& Açıkgöz, Z. (2005). Aromatik Bitkilerin Hayvansal Ürünlerde Antioksidan Etkileri. Hayvansal Üretim. 46(1).

Park, C. (2018). Medicinal Properties of Garlic and Its Derivatives (Doctoral dissertation). Faculty of Baylor University. Waco. Texas.

Pecher, T., \& Böck, A. (1981). In vivo Susceptibility Of Halophilic And Methanogenic Organisms To Protein Synthesis Inhibitors. FEMS Microbiol. Letters. 10; 295-297.

Ryu, J. H., \& Kang, D. (2017). Physicochemical Properties. Biological Activity. Health Benefits. and General Limitations of Aged Black Garlic: A Review. Molecules. 22 (6). 919.

Sasaki, J. I., Kita, T., Ishita, K., Uchısawa, H., \& Matsue, H. (1999). Antibacterial Activity of Garlic Powder Against Escherichia coli O-157. Journal of nutritional science and vitaminology, 45(6), 785-790.

Sasaki, J. I., Lu, C., Machiya, E., Tanahashi, M., \& Hamada, K. (2007). Processed Black Garlic (Allium sativum) Extracts Enhance Anti-tumor Potency Against Mouse Tumors. Energy (kcal/100 g), 227, 138.

Sivropoulou, A., Kokkini, S., Lanaras, T., \& Arsenakis, M. (1995). Antimicrobial Activity of Mint Essential Oils. Journal of Agricultural and Food Chemistry, 43(9), 2384-2388.

Tassou, C., Koutsoumani, K., \& Nychas, G. J. (2000). Inhibition of Salmonella enteritidis and Staphylococcus aureus in Nutrient Broth by Mint Essential Oil. Food Research International. 33(34). 273-280.

Tepe, B., Daferera, D., Sökmen, M., Polissiou, M., \& Sökmen, A. (2004). In vitro Antimicrobial and Antioxidant Activities of the Essential Oils and Various Extracts of Thymus eigii M. Zohary et PH Davis. Journal of agricultural and food chemistry, 52(5), 1132-1137.

Yaşa, İ., Kahraman, Ö., Tekin, E., \& Koçyiğit, A. (2008). Isolation and Molecular Identification of Extreme Halophilic Archaea From Çamaltı Saltern. Ege Journal of Fisheries and Aquatic Sciences, 25(2).

Yorgancıoğlu, A. (2012). Bazı Uçucu Yağlarla Kollajen İçerikli Antimikrobiyal Krem Üretilebilirliği Üzerine Araştırmalar. Yüksek Lisans Tezi. Ege Üniversitesi. Fen Bilimleri Enstitüsü. 